\title{
América Latina: entre pontes, muros e oceanos
}

\author{
Latin America: between bridges, walls and oceans
}

\section{Roberta Sperandio TRASPADINI}

\begin{abstract}
Resumo: Este artigo é um convite à reflexão a partir da construção histórico-social de pontes e muros na América Latina manifestas em três movimentos: 1. Breves apontamentos sobre a história da construção de pontes e muros originados na conquista/colonização. 2. Conexões entre o passado e o presente da América Latina, com base em uma posição político-teórica sobre a interpretação da história das resistências. 3. Possibilidades de consolidação de uma ponte de resistência no âmbito das universidades públicas brasileiras: a experiência da Universidade Federal da Integração Latino-Americana, na tríplice fronteira. A intenção é explicitar a dinâmica histórica da luta de classes no continente que, apesar do genocídio e da invisibilidade orquestrados pela classe dominante, segue viva, pulsante e com possibilidades sempre abertas rumo à emancipação. As pontes e os muros, naturais, sociais, servirão de mediação para a construção textual relativa à relação histórica do homem com a natureza.
\end{abstract}

Palavras-chave: Trabalho. Terra. América Latina. Pontes.

Abstract: This article is an invitation to reflection from the historical-social construction of bridges and walls in Latin America manifest in three movements: 1. Brief notes on the history of the construction of bridges and walls originated in conquest / colonization. 2. Connections between past and present in Latin America, based on a political and theoretical position on the interpretation of the history of resistance. 3. Consolidation Possibilities of a resistance bridge within the Brazilian public universities: the experience of the construction of the Federal University of Latin American Integration, in the triple border. The intention is to outline the historical dynamics of the class struggle on the continent, despite the genocide and invisibility orchestrated by the ruling class, is still alive, pulsating and always open possibilities towards emancipation. Bridges and walls, natural, social, serve mediation for textual construction on the historical relationship between man and nature.

Keywords: Labor. Land. Latin America. Bridges.

Submetido em: 30/11/2015. Aceito em: 3/o1/2016.

\section{Breve introdução}

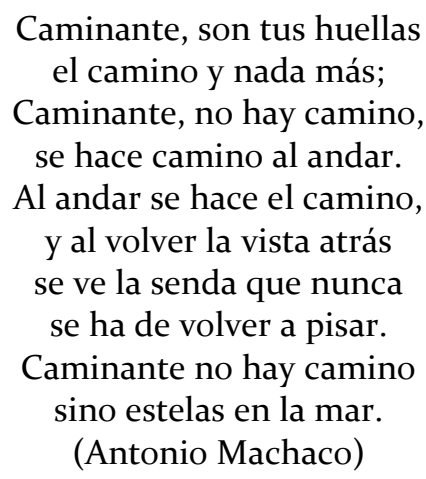

\footnotetext{
${ }^{1}$ Economista. Doutoranda do programa de Pós-graduação Conhecimento e inclusão social, Faculdade de Educação, da Universidade Federal de Minas Gerais (UFMG, Brasil). Professora do curso de Relações Internacionais da Universidade Federal da Integração Latinoamericana (UNILA, Brasil). Integrante do Grupo Interdisciplinar de Estudos e Pesquisa sobre Capitais Transnacionais, Estado, classes dominantes e conflitividade na América Latina e Caribe (GIEPTALC). Professora Militante da Escola Nacional Florestan Fernandes (ENFF, Brasil). E-mail: <robertatraspadini@gmail.com>.
}

Argumentum, Vitória (ES), v. 8, n.1, p. 27-47, jan./abr. 2016. 


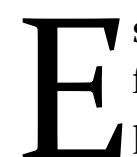

ste artigo é um convite à reflexão a partir da produção social de pontes e muros manifestos em três movimentos: 1. Breves apontamentos sobre a história da construção de pontes e muros originados na conquista/colonização do continente americano. 2. Conexões entre passado e presente da América Latina, com base em uma posição político-teórica pautada na história das resistências. 3. Possibilidades de consolidação de uma nova ponte de resistência no âmbito das universidades públicas brasileiras à atual crise civilizatória do capital: a experiência da Universidade Federal da Integração Latino-Americana (UNILA), na tríplice fronteira. Para conectar os três movimentos, serão utilizados recursos didático-pedagógicos a fim de manifestar, no encontro entre várias linguagens, as múltiplas pontes, muros, sobre as quais passam - e são impedidos - oceanos de conhecimentos historicamente em disputa na América Latina.

Há vários tipos de pontes: objetivas e subjetivas, concretas e abstratas, acadêmicas e populares. Entre as pontes objetivas-concretas, há pontes sociais, produzidas pelos seres humanos em suas relações diretas com a natureza e os demais seres, fruto do trabalho. Entre as pontes sociais, há pontes naturais produzidas pelo próprio meio ambiente, que permitem o ser humano, com base em suas necessidades e criatividades antever processos, traçar rumos, construir caminhos, sobreviver.

Sejam pontes e muros naturais, ou sociais, o que permite o ser humano interagir com o meio e recriá-lo, recriando-se, é o trabalho. O trabalho é a força ontocriativa de produção do ser social em sua histórica relação indissociável com a natureza. A produção material de vida, subsumida como geração privada na produção apropriação do fruto do trabalho no específico modo de produção capitalista não é destino, nem fim último da humanidade. É um caminho manifesto desde uma perspectiva dominante, que se pretende único e onipotente, ao longo da histórica caminhada dos seres sociais, sempre em movimento. Fugir dos múltiplos desertos, criar novos abrigos, nominá-los e recriá-los com os materiais fornecidos pelo meio e elaborados paulatinamente pelo ser social, através de seu trabalho, eis uma das características de ser, dos seres humanos.

\section{A construção de pontes e muros na conquista/ colonização da América}

Entre as pontes naturais, aponta-se - em meio a muita polêmica entre os historiadores sobre a raiz do continente e sua relação com o mundo - o Estreito de Bering como possível ponto de conexão entre os continentes asiático e americano, a 14000 anos atrás. Através desse caminho natural, de gelo, pesquisadores da história da América, investigam a relação direta entre os povos, a conexão entre as culturas e a produção do novo com base no encontro possibilitado pelos caminhos naturais de conexão entre os continentes.

A conquista foi uma ponte erguida para a dominação violenta de um povo sobre o outro. Através dela os conquistadores ergueram muros, quase intransponíveis de produção do terror e de uma verdade que enterrou, junto com milhões de corpos, processos de produção de vida, diversos e diferentes do que era produzido no mundo do conquistador. A educação formal, a cultura evangelizadora, a dominação da terra e as novas formas de escravização do trabalho, apresentaram-se como a "civilização" dos "bárbaros".

Argumentum, Vitória (ES), v. 8, n.1, p. 27-47, jan./abr. 2016. 
Nas palavras de Eduardo Galeano, em seu artigo para o Le Monde Diplomatique de 2005, intitulado Os demônios do demônio:

A conquista da América foi uma longa e difícil tarefa de exorcismo. Tão arraigado estava o Demônio nestas terras, que quando parecia que os índios se ajoelhavam devotamente ante a Virgem, estavam na realidade adorando a serpente que ela amassava com o pé; e quando beijavam a Cruz não estavam reconhecendo ao Filho de Deus, mas estavam celebrando o encontro da chuva com a terra. Os conquistadores cumpriram a missão de devolver a Deus o ouro, a prata e outras várias riquezas que o Demônio havia usurpado. Não foi fácil recuperar o tesouro. Ainda bem que de vez em quando recebiam alguma pequena ajuda de lá de cima. Quando o dono do inferno preparou uma emboscada em um desfiladeiro, para impedir a passagem dos espanhóis em busca da prata de Cerro Rico de Potosi, um arcanjo baixou das alturas e lhe deu uma tremenda surra. (GALEANO, 2005, não paginado).

Sobre o impacto da criativa condição humana de aproveitar o natural em seu benefício, ao construir processos sociais, vai dando novas tonalidades ao meio e a si mesmo. Ciro Flamarion Cardoso (1982, p. 20-21), especialista na história da América Latina, argumenta que,

[...] como ainda não está provada a existência de 40000 ou mesmo 20000 anos atrás de embarcações capazes de atravessar o estreito, a maioria dos pesquisadores vincula as primeiras migrações à última glaciação, quando a água retida nas geleiras continentais fez baixar o nível do mar, aparecendo na região do estreito e das ilhas Aleutas, todo um subcontinente, a Beríngia. [...] É interessante notas que o estreito às vezes se congela e pode ser atravessado a pé. (CARDOSO, 1982, p. 20-21).

O que ontem foi o ponto de interação entre dois oceanos que correm e produzem processos sociais diferenciados nos povos do Ártico e do Pacífico, hoje é a fronteira de dois históricos rivais na geopolítica e geoeconomia, EUA-Rússia. No gelo/degelo natural, diversas civilizações constroem processos sociais cuja racionalidade convoca a profundas reflexões sobre os limites e possibilidades da ideia do progresso e do desenvolvimento constituídos pelo próprio ser social.

À medida que o ser humano cria novos processos em meio aos naturais, gera produções materiais/sociais que transformam, ao mesmo tempo, o meio e os seres que o materializam. Com isto refunda o sentido da vida, da relação social e do estágio de desenvolvimento das forças produtivas.

A força da natureza vinculada à ação humana explicita a cada período histórico processos e limites à continuidade de vida na terra, como o resultado de uma intenção política de classe, de identificação social de um grupo sobre os demais, acerca da utilização da natureza e do trabalho para determinado fim. Engels (1876), em um belo texto sobre o desenvolvimento do homem em sua relação com a natureza manifesta múltiplas pontes quando argumenta que:

Aprendemos cada dia a compreender melhor as leis da natureza e a conhecer tanto os efeitos imediatos como as consequências remotas de nossa intromissão no curso natural de seu desenvolvimento. Sobretudo depois de grandes progressos alcançados neste século pelas ciências naturais, estamos em condições de prever, e portanto, de controlar cada vez melhor as remotas consequências naturais de nossos atos na produção pelo menos dos mais correntes. E quanto mais isso seja uma realidade, mais os

Argumentum, Vitória (ES), v. 8, n.1, p. 27-47, jan./abr. 2016. 
homens sentirão e compreenderão sua unidade com a natureza, e mais inconcebível será essa ideia absurda e antinatural da antítese entre o espírito e a matéria, o homem e a natureza, a alma e o corpo, ideia que começa a difundir-se pela Europa sobre a base da decadência da antiguidade clássica e que adquire seu máximo desenvolvimento no cristianismo. (ENGELS, 1876, p. 24).

Na América os povos originários ou migrantes, instituíram culturas milenares. Maias, astecas e incas construíram pontes de todos os tipos. Conectaram territórios, criaram ciências, geraram novos mecanismos de viver em relação com o meio e os seres. E construíram muros. Alguns para resistir às intempéries naturais, outros para preservar-proclamar guerras, além de instituir poderes de todos os tipos- econômico, social, cultural, mítico.

Somente o ser humano em sua condição ontocriativa é capaz de nominar, recriar e dar sentido político concreto às pontes e aos muros. No caso da conquista/colonização, não foi nem por pontes, nem por muros de concreto que ocorreu a invasão territorial da América. Foi por mares e oceanos, pontes projetadas desde uma estrutura lógica de poder. As navegações trouxeram para o Atlântico o que até então se disputava no Mediterrâneo. A busca das Índias gerou o inusitado encontro exploratório sobre as Américas no período da transição (do feudalismo para o capitalismo).

A descoberta, com o fim mercantil, fortaleceu as guerras entre potências na Europa que concorriam pela dominação de territórios dentro e fora deste continente (Espanha, Portugal, Holanda). A conquista/colonização da América mescla-se com a conquista/colonização de povos e territórios em outras partes, e ambas geram riquezas originárias acumuladas através do saqueio, da pilhagem, dos vários crimes e castigos cometidos pelos dominantes europeus em terras estrangeiras.

O objetivo das guerras por conquista/colonização, dentro e fora do continente europeu, foi o de colocar em movimento um novo modo de produzir vida, ancorado na propriedade privada da terra e dos meios de produção. O nascente poder burguês consolidou o Estado de direito e criou o aparato legal que sustentaria a legitimação da liberdade condicionada à compra e venda dos meios de produção e da força de trabalho.

Na Europa, o trabalhador foi transformado tanto em um eterno migrante por necessidade, em busca de trabalho assalariado em outros lugares, sob as condições desenhadas legalmente pelos proprietários privados ordenadores do Estado de direito, como em integrante de uma massa de desempregados necessitados da ajuda pública desses mesmos protagonistas da nova ordem. Nas colônias da América, povos originários foram dizimados e/ou "condenados" ao trabalho escravo em algumas partes, e ao trabalho "livre" em outras, sob a consigna da liberdade desenhada desde a Europa, cujo fim era o mesmo: de torná-los trabalhadores escravos-livres para a geração da produção social e apropriação privada da riqueza capitalista. Nas palavras de Marx (1989):

Marcam época, na história da acumulação primitiva, todas as transformações que servem de alavanca à classe capitalista em formação, sobretudo aqueles deslocamentos de grandes massas humanas, súbita e violentamente privadas de seus meios de subsistência e lançadas no mercado de trabalho como levas de proletários destituídos de direitos. A expropriação do produtor rural, do camponês, que fica assim privado de suas terras, constitui a base de todo o processo. A história dessa expropria-

Argumentum, Vitória (ES), v. 8, n.1, p. 27-47, jan./abr. 2016. 
ção assume coloridos diversos nos diferentes países, percorre várias fases em sequência diversa e em épocas históricas diferentes. Encontramos sua forma clássica na Inglaterra que por isso nos servirá de exemplo. (MARX, 1989, p. 831).

As descobertas construíram pontes e muros em mundos habitados, materialmente erguidos em grandes construções, com pontes, muros e oceanos conhecidos e dominados. Em outros termos, a história da conquista e colonização tem um ponto de partida: um continente, próprio, cheio de histórias e vidas anterior à sua chegada. Por mais que se imprima um novo ritmo, baseado em novos muros, o anterior resiste, imprime novas formas e conteúdos no jogo da violenta dominação.

A história do "bem-sucedido" caráter mercantil do empreendimento colonial nasce e se desenvolve em um contexto de lutas que torna presente a memória materializada na terra, nos povos e nas construções sociais levantadas em períodos anteriores à colonização.

Nos termos de Cardoso (1982)

As violentas lutas de classes que denominamos habitualmente "reformas liberais", travadas no século XIX, e que deram origem às estruturas contemporâneas dos países Indo-América - México, Guatemala, El Salvador, Colômbia, Equador, Peru e Bolívia - são incompreensíveis sem um elemento agrário indígena e mestiço que remete, em maior ou menor medida, a realidades geradas no passado pré-colombiano, embora depois tenham sido profundamente transformadas e às vezes desfiguradas. (CARDOSO, 1982, p. 112).

Assim como os seres humanos são capazes de se refazer, ao recriar suas relações com o mundo, nada está definido que esta recriação se dará em harmonia com o meio e os demais seres. A opção, sempre política, está posta a ser tomada por várias vias.

Humanizar e desumanizar, conquistar e libertar, guerrear e interagir, são possibilidades cuja opção está sempre nas mãos daqueles que detém um maior desenvolvimento das forças produtivas. Especificamente no caso da América, os dominantes do lado de lá do oceano, definiram do lado de cá do outro oceano, pela desumanização, conquista e pela guerra. O resultado foi a consolidação hegemônica, mas não única, de uma América Latina para os Europeus vitoriosos lá, dominantes neste então, lá e cá.

O filósofo Enrique Dussel (200o) ao tratar do tema da irracionalidade racional, explicita esta violenta construção histórico social, ao afirmar que:

El ego cogito moderno fue antecedido en más de un siglo por el ego conquiro (Yo conquisto) práctico del hispano-lusitano que impuso su voluntad (la primera "Voluntad-de-Poder" moderna) al indio americano. La conquista de México fue el primer ámbito del ego moderno. Europa (España) tenía evidente superioridad sobre las culturas aztecas, mayas, incas, etc., en especial por sus armas de hierro-presentes en todo el horizonte euro-afro-asiático-. Europa moderna, desde 1492, usará la conquista de Latinoamérica (ya que Norteamérica sólo entra en juego en el siglo XVII) como trampolín para sacar una "ventaja comparativa" determinante con respecto a sus antiguas culturas antagónicas (turco-musulmana, etc.). Su superioridad será, en buena parte, fruto de la acumulación de riqueza, experiencia, conocimientos, etc., que acopiará desde la conquista de Latinoamérica. (DUSSEL, 2000, p. 29).

Argumentum, Vitória (ES), v. 8, n.1, p. 27-47, jan./abr. 2016. 
Na tentativa onipotente de consolidação estrutural hegemônica dominante sobre o mundo, ato violento praticado por alguns poderosos europeus sobre vários territórios, deu-se a invisibilidade dos povos originários. Tal violência foi o resultado de uma disputa que ergueu muros e pontes rumo à difamação, estereotipação do outro.

A imagem dos povos originários veiculada desde a despótica e unilateral perspectiva dominante é propagada como verdade absoluta desde a narrativa dos "vencedores" a ser apropriada pelos "vencidos". Esta imagem, consolidada objetiva e subjetivamente entre pontes e muros do conhecimento, ganha projeção e alimenta a ideia do ser menos inerente ao conquistado.

As culturas originárias são ainda hoje desconhecidas para parte expressiva da população latino-americana, em especial a residente na região sul, hemisfério habitado por povos nômades, à diferença das culturas anteriores enraizadas em lugares concretos, como a região andina e a região central (Mesoamérica), locais em que residiam aproximadamente $90 \%$ da população do continente até o século XV.

Mas o que as torna invisíveis na história, sendo tão reais ainda hoje? Que tipo de pontes e muros foram erguidos na América Latina - entre o passado colonial e o presente - capazes de manter soterrada a história viva do continente? Pois, ainda que as pirâmides, as cidades préhispânicas, as culturas milenares presentes nas vidas de nossos povos, seja real, a cotidianidade ideológica hegemônica tende, intencionalmente, a apresentá-las como "inexistente" e "inferior".

Existem interesses por trás da negação dessas histórias. Com base nesses interesses foram construídas pontes e muros e derramados oceanos de sangues na história dos genocídios oriundos destas construções materiais da execução do poder. A história assim pensada narra milhões de mortes por baixo dos concretos muros de nossa América. Muitas fronteiras sociais foram delimitadas ao longo dos últimos 515 anos. Terão sido capazes de conter esse universo repleto de vida inerente ao Sumak Kawsay (bem viver), uma vez que não conseguiram aniquilá-lo?

\title{
2 Passado e presente da América Latina: entre pontes e muros de dominação e resis- tências
}

\author{
Soy... soy lo que dejaron \\ Soy toda la sobra de lo que te robaron \\ Un pueblo escondido en la cima \\ Mi piel es de cuero, por eso aguanta cualquier clima \\ Soy una fábrica de humo \\ Mano de obra campesina para tu consumo \\ Frente de frío en el medio del verano \\ El amor en los tiempos del cólera, ¡mi hermano! \\ Si el sol que nace y el día que muere \\ Con los mejores atardeceres \\ Soy el desarrollo en carne viva \\ Un discurso político sin saliva \\ Las caras más bonitas que he conocido \\ Soy la fotografía de un desaparecido
}




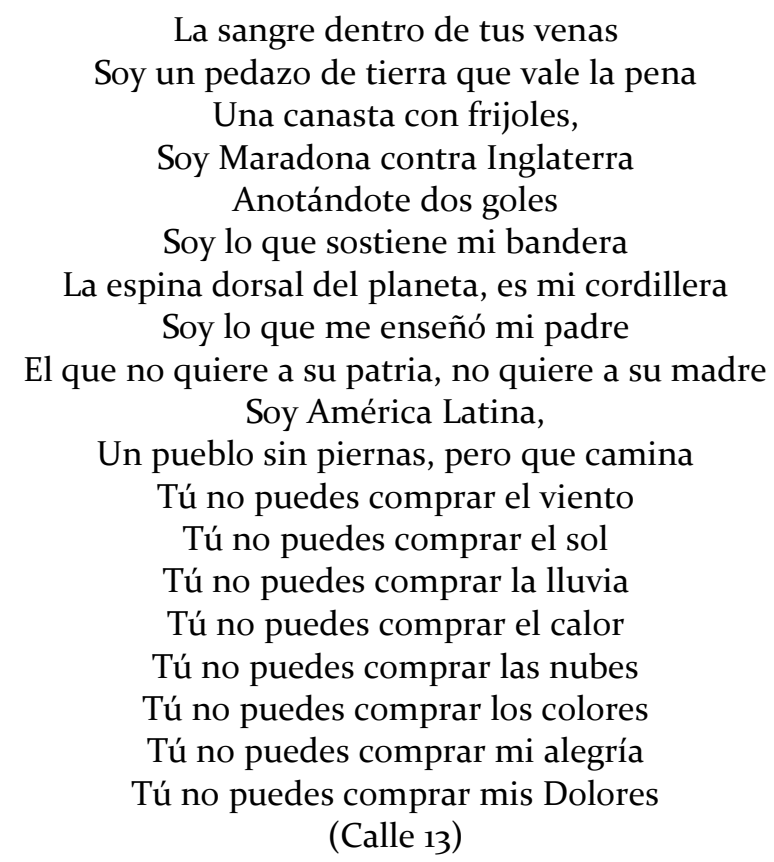

A história da América Latina se expressa, desde o século XV, na luta permanente entre ser para si e/ou ser para outros. Mas esta história não é única nem isolada. Conecta-se com outras histórias vividas por vários povos em seus territórios no passado e no presente. Compreender desde este lado do atlântico a história da transição ocorrida na Europa (do feudalismo para o capitalismo) que revolucionou a forma de produzir vida em várias partes do mundo concomitantemente, entre os séculos XV-XVII, nos obriga a discutir as raízes e impactos da originária acumulação de capital geradora deste processo.

Freire (1987) sustentava em Pedagogia do Oprimido que "[...] não há vida sem morte, assim como não há morte sem vida, mas há também uma morte em vida. E a morte em vida é exatamente a vida proibida de ser vida" (FREIRE, 1987, p. 99).

Edgard Lander (2005) constrói seus argumentos no mesmo sentido ao sustentar que

[...] a conquista ibérica do continente americano é o momento inaugural dos dois processos que articuladamente conformam a história posterior: a modernidade e a organização colonial do mundo. Com o início do colonialismo na América inicia-se não apenas a organização colonial do mundo mas, simultaneamente, a constituição colonial dos saberes, das linguagens, da memória ... e do imaginário.... Dá-se início ao longo processo que culminará nos séculos XVIII e XIX e no qual, pela primeira vez, se organiza a totalidade do espaço e do tempo. Todas as culturas, povos e territórios do planeta, presentes e passados, numa grande narrativa universal. Nessa narrativa, a Europa é ou sempre foi simultaneamente o centro geográfico e a culminação do movimento temporal. Nesse período moderno [...] dão-se os primeiros passos na articulação das diferenças culturais em hierarquias cronológicas. (LANDER, 2005, p. 10).

A terra e o trabalho são as duas características centrais geradoras de conexão entre o ontem e o hoje. Bases sobre as quais a América Latina segue vital na continuidade de dominação de classe tanto do Norte sobre o Norte, quanto do Norte sobre o Sul. 
Os povos originários foram subsumidos à dinâmica da violência colonial ao mesmo tempo em que os povos europeus foram expulsos do campo, numa aparente situação de liberdade vinculada à condição de não mais possuírem os meios de produzir vida através de seu trabalho. De camponeses servis foram transformados em trabalhadores livres, sem terras e com condição de vida historicamente dependente de outros seres humanos proprietários privados de todos os meios de produção. Sob o domínio de um nasce a condição do outro subsumida ao modo de produzir vida a partir do interesse privado do proprietário da terra e das ferramentas para trabalhá-la na forma mercantil.

Este mecanismo geral de dominação sobre os corpos e a natureza, expressa a expropriação e a exploração como inerentes ao desenvolvimento do capitalismo, ainda que varie a forma como se manifestam nos territórios (no caso específico da América Latina a superexploração da força de trabalho vai dimensionar particularidades concretas da produção de riqueza capitalista no continente). Situação que põe em movimento em todo período histórico, lutas por resistir, liberar-se, superar a ordem dominante.

Os povos originários partiam de uma premissa de ocupação territorial, de estruturação organizativa geopolítica e de conformação de relações sociais cujas bases não eram a valorização do capital. No entanto, após 1500, a violência inerente à invasão e conquista, mudou o rumo, alterou as dinâmicas, gerou um processo de subordinação colonial, sem com isto, aniquilar, ainda que pretendesse, a memória, a história e a presença das lutas pelo direito a terra e ao trabalho livre no continente.

A história sangrenta vivida na América Latina se mescla com as demais violências vividas no próprio continente europeu, imersa na totalidade do movimento do capital em cada uma das particularidades ocupadas com o fim mercantil. Tanto lá, quanto cá, muitos camponeses perderam suas vidas, outros ao lutarem por elas, foram ou deportados, ou escravizados de várias formas, inclusive com dívidas impagáveis que os forçava a migrar. Essa é parte da história do campesinato latino-americano que mescla povos originários, com povos forçados a migrar, na composição da história da luta de classes no continente.

A partir da narrativa da história oficial dominante, desenhava-se o marco do encontro com um continente primitivo, sobre-humano, cuja figura mítica do monstro era reforçada pela emblemática visualização da imagem do moderno, do avançado, frente ao que deveria ser colonizado, evangelizado, domesticado. A idade da razão nascia assim das múltiplas trevas que não haviam ficado para trás em plena era das luzes. Os fantasmas do período anterior seguiriam materializados em figuras humanas nos processos posteriores. Tudo isto, resultado concreto da ação do homem sobre o homem e sobre a natureza.

Galeano (1989), um dos principais autores do pensamento e sentimento latino-americano, em seu clássico texto, As veias abertas da América Latina (1972), relata os vários sentidos que podem ser dados à história neste continente a partir da forma/conteúdo como concebem o mundo:

Para os que concebem a História como uma disputa, o atraso e a miséria da América Latina são o resultado de seu fracasso. Perdemos; outros ganharam. Mas acontece que aqueles que ganharam, ganharam graças ao que nós perdemos: a história do subdesenvolvimento da América Latina integra, como já se disse, a história do de-

Argumentum, Vitória (ES), v. 8, n.1, p. 27-47, jan./abr. 2016. 
senvolvimento do capitalismo mundial. Nossa derrota esteve sempre implícita na vitória alheia, nossa riqueza gerou sempre a nossa pobreza para alimentar a prosperidade dos outros: os impérios e seus agentes nativos. Na alquimia colonial e neocolonial, o ouro se transforma em sucata e os alimentos se convertem em veneno. Potosí, Zacatecas e Ouro Preto caíram de ponta do cimo dos esplendores dos metais preciosos no fundo buraco dos filões vazios, e a ruína foi o destino do pampa chileno do salitre e da selva amazônica da borracha; o nordeste açucareiro do Brasil, as matas argentinas de quebrachos ou alguns povoados petrolíferos de Maracaibo têm dolorosas razões para crer na mortalidade das fortunas que a natureza outorga e o imperialismo usurpa. A chuva que irriga os centros do poder imperialista afoga os vastos subúrbios do sistema. Do mesmo modo, e simetricamente, o bem-estar de nossas classes dominantes - dominantes para dentro, dominadas de fora - é a maldição de nossas multidões, condenadas a uma vida de bestas de carga. (GALEANO, 1989, p. 5).

Na mesma perspectiva Paulo Freire em Pedagogia do Oprimido (1987) definia a teoria da ação antidialógica nos marcos de quatro fundamentos característicos da dominação - conquista, divisão, manipulação, invasão cultural- e explicitava que:

Todo ato de conquista implica num sujeito que conquista e num objeto conquistado. $\mathrm{O}$ sujeito da conquista determina suas finalidades ao objeto conquistado, que passa, por isso mesmo, a ser algo possuído pelo conquistador. Este, por sua vez, imprime sua forma ao conquistado que, introjetando-o, se faz um ser ambíguo. Um ser, como já dissemos, hospedeiro do outro. (FREIRE, 1987, p. 78).

De tal forma se caracteriza a conquista como guerra, violência, para a dominação que situações estruturadas desde a lógica do conquistador como o patriarcado e o colonialismo não foram somente o resultado histórico da vitória de uma nação sobre as outras. Estas condições mercantis constituem a vitória em diversos territórios de um modo de operar de uma classe sobre a outra, que não teme calar, denegrir, violar as próprias construções como forma de permanecer e perpetuar sua estrutura de poder.

A história da América Latina é ao mesmo tempo a história violenta do capitalismo sobre os povos em todos os territórios nos quais ele operou com sua ordem ditatorial cujo princípio é o da expropriação, espoliação e exploração da força de trabalho.

Apesar da violência colonial e pós-colonial dos invasores europeus, América Latina permanece viva como território de disputa. Ante a tirania atual da transgenia, da produção com veneno e da superexploração da força de trabalho no campo e na cidade, a luta dos povos originários/camponeses demarca os múltiplos sentidos a serem dados à terra, ao trabalho, ainda sob o domínio sangrento do capital. Para os povos indígenas, por exemplo, a terra mãe, origem de toda a vida, não é uma mercadoria com valor de uso e valor de troca. Bem viver ou Sumak Kawsay, em quéchua significa vida em plenitude e opõe-se ao llaki kawsay, mal viver, em nossa América Latina (AbyaYala).

O estudioso equatoriano Carlos Viteri (2003) define da seguinte forma "Sumak kawsay es 'buen vivir' o 'vida armónica'[...] aquello que los sarayakurun, conciben como el sentido ideal de la vida. Es un concepto formado por dos palabras: súmak, lo bueno, lo bello, lo armónico, lo perfecto, lo ideal y kawsay, vida, existencia” (VITERI, 2003, p. 46).

Argumentum, Vitória (ES), v. 8, n.1, p. 27-47, jan./abr. 2016. 
A consolidação do moderno Estado de direito na Europa, no século XIX, foi um dos elementos centrais de conformação da estrutura jurídica formal de atuação dos proprietários privados da terra e dos meios de produção, princípio organizativo de uma suposta nova era mais avançada, o capitalismo industrial. Este processo consolidou, no papel, o que até então era fruto de uma dinâmica de poder moral, cujo princípio não era tão distinto: terra e trabalho pertencentes a poucos donos, sob a violenta ordem socialmente construída sobre os corpos de muitos.

No mesmo período, parte expressiva das "independências" ocorridas na América Latina demarcava a vitória dominante do projeto liberal burguês que instituía o direito individual de propriedade como célula-tronco da ocupação territorial no continente. $O$ desenvolvimento das forças produtivas foi, aos poucos, tendendo a naturalizar as relações produzidas socialmente entre os seres sociais, destes com a natureza e demais seres.

Como definido por Wallerstein em seu texto Análise do Sistema Mundo (2005), a consolidação dos Estados Nacionais formalizou o tema das fronteiras, dos limites e das novas relações multilaterais de poder no âmbito do sistema-mundo moderno. Nas palavras do autor:

La soberanía era una afirmación de autoridad no sólo interna sino externamente; esto es, vis-á-vis otros estados. Fue, en primer lugar, una afirmación de fronteras fijas, dentro de las cuales un estado determinado era soberano, y por lo cual dentro de ellas ningún otro estado tenía el derecho de ejercer ningún tipo de autoridad: ejecutiva, legislativa, judicial, o militar. Más aún, estas afirmaciones por parte de los estados acerca de la no "interferencia" de otros estados en sus asuntos domésticos ha sido observada más fielmente en su violación que en su cuidadoso seguimiento. Pero la mera afirmación ha servido, sin embargo, para limitar el grado de injerencia. Tampoco han permanecido las fronteras inmutables. Los reclamos limítrofes entre estados han sido una constante. Sin embargo, en cualquier momento dado, existen realidades de facto en cuanto a las fronteras dentro de las cuales se ejerce la soberanía. [...] Existe una característica fundamental más en cuanto a la soberanía. Es una afirmación, y las afirmaciones significan poco y nada a menos que sean reconocidas por los demás. Los demás pueden no respetarlas afirmaciones, pero eso es en muchos sentidos mucho menos importante que el que las reconozcan formalmente. La soberanía es antes que nada una cuestión de legitimidad. Y en el sistema-mundo moderno, la legitimidad de la soberanía requiere el reconocimiento recíproco. La soberanía es un intercambio hipotético, en el que dos bandos potencialmente (o en verdad) en conflicto, respetando la realidad de facto del poder, intercambian semejante reconocimiento como estrategia menos costosa. (WALLERSTEIN, 2005, p. 45).

Guerras, violências institucionais arraigadas, ideologia criminosa sobre o direito à vida e à terra, geraram uma forma predominante de ser urbana, individual, arraigada na centralidade do dinheiro, com a intencionalidade clara de desvincular a vida cotidiana atual da história e memória das lutas sociais ocorridas ao longo dos mais de quinhentos anos no continente.

Terra e trabalho estão em permanente disputa. Como a história é movimento, possibilidade aberta nas lutas concretas, os povos desde suas raízes (terra e trabalho), ontem e hoje, se levantam e reivindicam o direito ao bem viver que não está dissociado da emancipação a ser conquistada pela luta de classes em todos os continentes. Desta fusão entre as histórias surgem novas sínteses, fruto de aprendizagens coletivas de classe que tecem caminhos possíveis para transformar a ordem dominante.

Argumentum, Vitória (ES), v. 8, n.1, p. 27-47, jan./abr. 2016. 
Na atualidade, em vários países da América Latina, com destaque para Bolívia, Equador, Paraguai, Uruguai e Venezuela, os povos originários se levantaram e, em pleno jogo da disputa, via voto, conseguiram imprimir outros horizontes em meio ao jogo hegemônico do capital. Estes países assumiram uma construção identitária cuja representatividade se materializa em idiomas e culturas originárias, com produção de vida para além do capital.

Vale reforçar este fato. Segundo o documento da Comissão Econômica Para América Latina e Caribe (CEPAL), Los pueblos indígenas de América Latina (2014), nas estimativas realizadas pelos países em 2010, 8,3\% da população da América Latina é caracterizada como indígena distribuída em 826 povos, cuja principal característica é a diversidade cultural, linguística e social. Enquanto na Bolívia $62 \%$ da população é composta por indígenas, com 39 grupos diferentes, ainda que predominem os quéchuas 1,84 milhões e os aymaras 1,6 milhões, no Brasil, apenas $0,5 \%$ da população é indígena e está distribuída em 70 povos.

Outros Estados mais vinculados à ordem dominante como o caso do Brasil, em meio à dinâmica subimperialista (MARINI, 1969) no continente, geraram processos contraditórios cuja disputa pode potencializar, ou não, as sementes germinadas pelo primeiro grupo. Este é outro tema central dos debates a ser aprofundados: a questão do desenvolvimento. Discussão que desde a década de 1940, ganha evidência na produção do conhecimento na América Latina, e tem como marco, do debate mais intenso, o fim dos anos 1960 - em meio à Guerra Fria e aos processos de ditaduras vividos no continente - quando o receituário consolidado pela CEPAL já dera resultados manifestos em países como Brasil, Argentina, México e Uruguai.

"Desenvolvimento e dependência" foi um debate que expressou leituras distintas com posicionamentos políticos concretos e antagônicos sobre o sentido político explicado e proposto para o processo de disputa sobre os rumos econômicos, políticos e militares do continente. Dentro da ordem capitalista, as revisões da CEPAL e as perspectivas teóricas da (inter)dependência de Fernando Henrique e Enzo Faletto, se contrapunham às leituras contra hegemônicas presentes nas interpretações de Gunder Frank, Vânia Bambirra, Theotônio dos Santos e Ruy Mauro Marini, autores marxistas do debate da dependência.

Na ênfase dada à dependência desde a perspectiva marxista, vale destacar a posição de Marini (2011) sobre a Dialética da dependência, uma vez que este autor segue invisível dos debates das ciências sociais no Brasil, fruto do resultado histórico de possuir uma práxis revolucionária, postura intelectual rigorosa e posição política antagônica à de Fernando Henrique Cardoso, quem despontou, não sem sua própria personificação, como grande expoente do debate.

Marini consolidou duas categorias analíticas centrais para o debate latino-americano, que demarcavam sua posição política acerca do estágio de desenvolvimento mercantil do continente nos séculos XVIII e XIX, e explicitava dois processos integrados: a) A função que cumpria América Latina na dinâmica geral de reprodução do capital, b) O papel do Brasil como potência capitalista na região. Superexploração (MARINI, 2011) e subimperialismo (MARINI, 1969) fundiam-se à exploração e ao imperialismo e expressavam a relação direta entre o particular e o geral na compreensão da totalidade do movimento do capital na economia mundial.

Argumentum, Vitória (ES), v. 8, n.1, p. 27-47, jan./abr. 2016. 
A perspectiva marxista da dependência forneceu, na opinião de Wallerstein (2005), um dos pilares do pensamento sistema-mundo, dado o giro que davam nas ciências sociais clássicas e modernas que pensavam a universalidade como eixo condutor da construção do poder e do saber. A estrutura de dominação de produção da riqueza capitalista está associada à dominação ideológica e cultural entrelaçada à extração de valor. Apesar de Wallerstein (2005) reforçar o papel da teoria marxista da dependência na história do pensamento crítico latinoamericano, sua leitura sobre as debilidades teóricas - eurocêntricas - dessa perspectiva, classificando-a de economicista, reforça a epistemológica decolonial em geral que, ao posicionar-se contra o eurocentrismo, tende a entendê-lo, na sua totalidade, como um movimento de dominação despótica. Esse tema merece um estudo próprio posto que deixa de fora os históricos processos de lutas, disputas passadas e presentes, fruto do avanço do modo de produção capitalista na Europa, ao mesmo tempo em que reforça a visão focalizada das lutas pensadas somente no território em que elas ocorrem (força do local). O que se apresenta como crítica à perspectiva eurocêntrica acaba refém da própria epistemologia em questão e deixa de fora, na totalidade do movimento dialético, as particularidades que a dão vida. Ou, ao contrário, pensa somente desde o local, sem fundi-lo à movimentação em geral do capital, nas particularidades em que ele atua.

A educação formal na América Latina nasce como princípio organizador do trabalho assalariado "livre". Educar para o trabalho é educar para o sentido da propriedade privada dos meios de produção e da busca pela sobrevivência por parte dos trabalhadores, mais ou menos, instruídos, no que os classificará como pouco/muito qualificados. A perspectiva dos níveis de educação formal, em especial na história da educação superior foi a de produzir um conhecimento científico sinônimo de qualificação técnica para os estágios de desenvolvimento do capital no continente. A dependência, categoria constitutiva do capitalismo dependente latino-americano está conectada com a forma-conteúdo da educação formal. Educar para servir à dinâmica de conexão subalterna, periférica, em relação às economias centrais.

O sentido de ser das universidades latino-americanas, projetado desde a perspectiva do capital foi, intencionalmente, desenhado para ser desde/para o outro, primeiro Europa, depois Estados Unidos. Assim, as "independências formais" consolidaram uma nova forma latente de prisão intelectual, epistêmica, dependente.

À dependência estrutural baseada na superexploração da força de trabalho se ergue a ponte da dependência epistêmica e da fusão das duas são consolidados os marcos do desenvolvimento do capitalismo dependente latino-americano. Na narrativa das "independências formais" nasce a dependência real e a produção de valor conecta-se com a produção epistêmica de um conhecimento dependente, gênese da forma-conteúdo geral de produção-apropriação da riqueza capitalista concentrada-centralizada em poucos territórios mundiais.

Mas, se a história da América Latina é de luta, em constante movimento de disputa de classes, é possível instituir o novo em meio ao velho modus operandi? Se sim, que desafios se abrem para esta construção?

Argumentum, Vitória (ES), v. 8, n.1, p. 27-47, jan./abr. 2016. 


\title{
3 UNILA: pontes/muros em construção
}

"Certa vez uma caneta foi passear lá no sertão

Encontrou-se com uma enxada, fazendo uma plantação.

A enxada muito humilde, foi lhe fazer saudação,

Mas a caneta soberba não quis pegar na sua mão.

E ainda por desaforo lhe passou uma repreensão."

Disse a caneta pra enxada não vem perto de mim, não

Você está suja de terra, de terra suja do chão

Sabe com quem está falando, veja sua posição

E não se esqueça a distância da nossa separação.

Eu sou a caneta dourada que escreve nos tabelião

Eu escrevo pros governos a lei da constituição

Escrevi em papel de linho, pros ricaços e pros barão

Só ando na mão dos mestres, dos homens de posição.

A enxada respondeu: de fato eu vivo no chão,

Pra poder dar o que comer e vestir o seu patrão

Eu vim no mundo primeiro, quase no tempo de Adão

Se não fosse o meu sustento ninguém tinha instrução.

Vai-te caneta orgulhosa, vergonha da geração

A tua alta nobreza não passa de pretensão

Você diz que escreve tudo, tem uma coisa que não

É a palavra bonita que se chama educação!

(Zico e Zeca)

A UNILA foi constituída com base em três processos indissociáveis: 1) latino-americanismo; 2) bilinguismo; e 3) integração. Como todo projeto aberto em um horizonte não revolucionário, a ordem para dentro e para fora é de construção lenta e gradual de novos mecanismos de produção coletiva, imersos em velhas estruturas do saber, na relação entre as universidades públicas, os movimentos sociais latino-americanos e os Estados partícipes.

Para consolidar estes processos a UNILA desenhou a seguinte missão, corroborada em seu estatuto:

\begin{abstract}
A UNILA tem por missão contribuir para a integração solidária e a construção de sociedades na América Latina e Caribe mais justas, com equidade econômica e social, por meio do conhecimento compartilhado e da geração, transmissão, difusão e aplicação de conhecimentos produzidos pelo ensino, a pesquisa e a extensão, de forma indissociada, integrados na formação de cidadãos para o exercício acadêmico e profissional e empenhados na busca de soluções democráticas aos problemas latinoamericanos. (UNILA, Art. 4., [2011].
\end{abstract}

A beleza potencial deste projeto, reforçado em seu caráter latino-americanista, deve ser encarada tanto dentro, quanto fora, de seus muros. O desenvolvimento prático de alicerces teóricos diferenciados se verifica na práxis. Se os seres sociais que a constroem seguirão a reprodução da práxis opressora, ou criarão outros sentidos para o quefazer universitário, eis uns dos temas-problemas em movimento. 
Há a possibilidade aberta dos seres sociais latino-americanos produzirem conhecimento a partir do encontro de referenciais epistêmicos concretizados pela classe trabalhadora ao longo da história das resistências em seus múltiplos e diversos espaços de lutas. Mas como toda possibilidade, sua efetivação depende de uma correlação de forças complexa em tempos não revolucionários e de transformações abruptas sobre o sentido da educação para além dos marcos do capital transnacional. O objetivo latino-americanista da UNILA pauta, a partir da realidade brasileira, uma revisão histórica sobre ser e sentir-se latino-americano. Tema que com base no subimperialismo brasileiro tende a ser subestimado na onipotência da projeção do modelo de desenvolvimento capitalista dependente brasileiro, como uma das maiores economias do mundo. Processo aparente de situação quantitativa que o descola, no mito da ideologia do desenvolvimento, da essência qualitativa comum do capitalismo dependente latino-americano.

As epistemologias históricas da classe trabalhadora do campo e da cidade na América Latina, ao serem colocadas em movimento dialógico, questionam a ordem dominante e demandam novos sentidos, projetos, para a concepção acadêmica e popular do conhecimento. Retomar esta concepção como indissociável, exige recuperar o que de melhor os sujeitos políticos - povos originários, afrodescendentes, e demais imigrantes trabalhadores - produziram ao longo de seus históricos processos de resistências, revoltas e revoluções no continente. Entre estas produções encontra-se o pensamento marxista latino-americano que, ancorado no materialismo histórico dialético, método disputa o sentido da produção de conhecimento científico e de sua relação direta com o método de direção política de classe, com o fim de gerar outro mundo necessário e possível.

É evidente que este é um dos horizontes de sentido manifestos na UNILA. E está longe de ser o processo hegemônico. Mas ao fazer-se presente na disputa, torna-se herdeiro de Mariátegui, Martí, Che Guevara, Marini e Bambirra e encarna a manifestação histórica das disputas em todos os espaços em que ela aparece.

O desafio, a partir desta perspectiva, é partir da realidade tal como ela se apresenta (trabalho alienado) e construir caminhos para concretizar a realidade tal como necessitamos (trabalho emancipado). Para isto, como sustenta Ribeiro (2014) é necessário consolidar um encontro de saberes de classes, gênero, raça e etnia que:

Capaz de se entrelaçar com a rica tradição cognoscitiva da América Latina que remonta a Waman Poma de Ayala no século 17; José Carlos Mariátegui e Víctor Raúl Haya de la Torre, nos anos 1920; a teoria da dependência na década de sessenta, associada a autores como Theotônio dos Santos, Gunder Frank, Ruy Mauro Marini e, em tempos mais recentes, à teologia da libertação do padre Gustavo Gutiérrez e a filosofia da libertação de Enrique Dussel, dentre outros (Ribeiro et al., 2009) apontariam para a especificidade da crítica à modernidade hegemônica que, não sendo especificamente latino-americana, guarda, contudo, no continente, fortes elos com um marxismo revisitado à luz da problemática das culturas e etnias rechaçadas na constituição das repúblicas bem como em sintonia com o debate contemporâneo das subjetividades. (RIBEIRO, 2014, p. 74).

Tratam-se de encontros que subvertem a ordem dominante e potencializam processos emancipatórios pautados em outro sentido de vida e de relações sociais que superam o sentido mercantil. Entre as diversas lutas, está a forma como se entende a construção coletiva

Argumentum, Vitória (ES), v. 8, n.1, p. 27-47, jan./abr. 2016. 
do conhecimento, a organização política da gestão e, não menos importante, o papel concreto que cumpre uma universidade que não se descola das necessidades políticas concretas dos povos com os quais ela interage e produz. Uma produção capaz de entender a história das relações sociais manifestas na consolidação da sociedade na qual se vive, para, a partir da conscientização, constatar a necessidade de outro sentido/sentir para o viver em comunidade.

Freire (1987) defendia a necessidade de uma postura diferente à do conquistador denominada por ele como pedagogia libertadora que partia da premissa de uma conscientização desde/com o outro, entendido como ser e não como ser coisificado. Segundo sua perspectiva:

\footnotetext{
Na medida em que a conscientização na, e pela revolução cultural, se vai aprofundando na práxis criadora da sociedade nova, os homens vão desvelando as razões do permanecer das sobrevivências míticas, no fundo, realidades forjadas na velha sociedade. Mais rapidamente então poderão libertar-se destes espectros que são sempre um sério problema a toda revolução, enquanto obstaculizam a edificação da nova sociedade. (FREIRE, 1987, p. 91).
}

Das atividades que estruturam pontes entre a UNILA e os movimentos sociais da Tríplice Fronteira destacam-se: a) Os cursos de graduação e de pós-graduação (educação do campo, educação indígena, questão agrária e línguas); b) O vínculo direto nas pesquisas e extensões; c) A participação orgânica nas atividades geradas pelos movimentos em seus próprios territórios (jornadas de agroecologia e cursos de formação dos movimentos sociais organizados no campo) e; d) Conferências e encontros cujos protagonistas sejam os movimentos sociais e demais células políticas da sociedade civil. Estes processos, com base na localização particular da Tríplice Fronteira, dão à UNILA um perfil diferenciado para aquilo que até então se projetou como universidade pública no continente.

Em se tratando de pontes simbólicas social e historicamente construídas, a partir do pensamento coletivo trabalhado em coletividade entre técnicos da educação, docentes e discentes, a UNILA deve ser capaz de projetar outro sentido a denominada "ponte da amizade", que na falsificação da ideia de irmandade expõe as mazelas históricas da dominação do Brasil sobre o Paraguai. Essa ponte levantou e levanta muros intransponíveis em que a superexploração dos povos guaranis é protagonizada pela dominação dos capitais brasileiros e internacionais que atravessam cotidianamente a ponte "da amizade" e introjetam seus hábitos e costumes corriqueiros. Como se fosse possível semear a amizade em terras fertilizadas pelo domínio e sentido do capital.

Os povos guaranis nas correntes do rio Paraguai traçam suas trágicas e resistentes histórias. Local em que os militares brasileiros defendem a ordem do progresso do capital imperante em cada época. O idioma guarani, presente na fronteira é um belo exemplo de que os muros levantados, ainda quando massacrem, oprimam, não são capazes de destruir totalmente a riqueza da resistência. Das contradições emanam as possibilidades. A caminhada sobre as pontes, ao abrir novos horizontes, projeta possíveis novos usos para além do mercantil, mas não sem disputa.

Na potencialidade da construção de novas pontes de integração, a UNILA dá um sentido particular ao caráter interdisciplinar. A centralidade que ganha o ciclo comum e o bilin-

Argumentum, Vitória (ES), v. 8, n.1, p. 27-47, jan./abr. 2016. 
guismo, através do encontro entre diferentes sujeitos da América Latina, ainda que mediado por muitas contradições, é diferente de toda a história do conhecimento universitário formal brasileiro São três semestres de América Latina e de bilinguismo em todos os cursos de graduação. O ciclo comum sobre América Latina começa com uma abordagem teórico-histórica e culmina nos debates contemporâneos sobre Estados, movimentos sociais e integração. Mas como todo processo educativo em avaliação contínua, o ciclo comum exige fazer uso da crítica e da autocrítica permanentes, a fim de que os sujeitos em aprendizagem coletiva possam lapidar esse processo, com o afã de fortalecer outro sentido concreto de integração no continente.

Através deste exercício político-epistêmico latino-americanista é possível perceber a possibilidade aberta de uma perspectiva diferenciada de interdisciplinaridade que tende, ao se afirmar, a gerar encontros e projetos coletivos, tanto entre docentes, como entre estes e os discentes e técnicos administrativos. São três professores de distintas áreas do conhecimento, (colaboradores e articuladores), atuando juntos, em cada uma das três disciplinas de Fundamentos da América Latina. O ciclo comum manifesta um rearranjo no sentido de aprendizagem coletiva e de socialização do conhecimento que de fato quebra com a ordem dominante das caixinhas técnicas da educação. Isto, associado ao caráter de integração com as demais universidades e movimentos da região, torna o desafio ainda mais instigante.

A concepção de fortalecimento da integração latino-americana cria condições para receber pesquisadores, estudantes, técnicos administrativos em educação, que contribuam na conformação de uma universidade aberta, plural e vinculada às demandas populares. Isto, em si mesmo, torna a consolidação da UNILA um projeto para além das fronteiras nacionais. E exige múltiplas revisões que vão desde o papel do Brasil na perspectiva da integração latinoamericana, até a revisão do sentido da produção do conhecimento nos processos de desenvolvimento dos países que compõem América Latina.

Como em toda universidade pública latino-americana, muitas questões estão em disputas, em jogo. E exigem paciência histórica, posicionamento político explícito e unidade de classe. Este último talvez seja o tema mais difícil de ser resolvido nos atuais desdobramentos do capital. Os resultados de décadas de superexploração da força de trabalho e de séculos de dominação/opressão mercantil sobre os trabalhadores do continente estão presentes não somente no domínio hegemônico do pensamento de direita na América Latina. Na crise estrutural do capital se abrem as fendas da crise estrutural do que se entende por pensamento, práxis, de esquerda na América Latina.

Para que a UNILA concretize de fato um projeto diferente, outros sujeitos, oriundos de várias partes de nossa América necessitam somar-se e contribuir na construção de algo verdadeiramente emancipatório, cujas fronteiras quando existam, sejam a da produção de um mundo sem exploradores nem explorados. Mas é importante destacar que um projeto potencial de construção de novas pontes em uma sociedade despótica, educada para a suposta liberdade mercantil, corre riscos concretos de permanecer como vários outros processos universitários cuja ordem é de continuidade da desordem implantada.

Outra contradição manifesta em um projeto com potencial diferenciação frente aos hegemônicos, diz respeito à construção de processos participativos em uma sociedade que

Argumentum, Vitória (ES), v. 8, n.1, p. 27-47, jan./abr. 2016. 
aprendeu a atuar de forma dependente, subsumida, representada formalmente por aqueles que disputam poderes institucionais. Isto exige limpar terrenos, demarcar territórios e avançar rumo a processos coletivos de reflexão que fundem, de fato, novas práxis no ambiente universitário.

Discutir processos de representação democrático-participativa em que a comunidade acadêmica tenha o mesmo poder decisório baseado em proporções políticas comuns e consolidar tais mecanismos sem promover debates que envolvam a sociedade em geral abre, no presente, antigos desafios da construção de projetos alternativos no continente. A unidade na diversidade do pensamento crítico latino-americano exige tempo de aprendizagem em uma era pautada pela intensificação da aceleração do tempo histórico.

As experiências históricas de lutas na América Latina são múltiplas, mas seguem desconhecidas por muitos sujeitos e precisam ganhar a visibilidade da construção sempre possível sobre o novo que germina em históricas terras. Sem levar isto em conta amplia-se o risco de colocar em xeque a construção coletiva de um projeto político diferenciado de universidade pública na América Latina. A paciência histórica torna-se vital em um cenário de corrosiva produção de vida ancorada no cotidiano imediato, vulnerável e precarizado como o atual.

Construir uma produção ombro a ombro, trilhar caminhos que revisem a lógica de compreensão sobre a ciência e sua relação com a política e conformar um projeto coletivo - em que a centralidade esteja na emancipação dos povos e nos direitos originários à terra e à dignidade de vida na relação com a mesma -, tornam-se os imperativos da UNILA na perspectiva crítica. Nos projetos em disputas nas Universidades em geral, e na UNILA em particular, a função social alternativa, de primazia protagonista da classe trabalhadora, deverá ser assumida coletivamente. Este projeto tem somente cinco anos. Seu processo de desenvolvimento, complexo e contraditório, demandará além de paciência, a inserção de muitos grupos na ocupação dos projetos necessários à Tríplice Fronteira.

Todo desafio exige paciência histórica, compromisso social com o papel da universidade em sua relação com a sociedade, e acima de tudo, respeito profundo com os conhecimentos postos em diálogo e em movimento em várias partes do mundo. A história da luta de classes aproxima os povos, reorienta as lutas e ressignifica o papel dos múltiplos conhecimentos, entre eles o científico e o popular. Processos que demarcam o papel das universidades públicas na sua relação direta com a necessidade dos povos.

É hora de plantar! A UNILA é uma entre as várias sementes em disputa na luta de classes. Como tal, necessita ser construída com base em princípios claros e com a paciência necessária para conceber o tempo-espaço histórico colocado para aqueles que lutam por outro processo societário. Em tempos não revolucionários, exige-se uma atuação coletiva que prime por uma postura ética, democrática e transparente, que tome como ponto de partida/chegada o compromisso com um conhecimento de alta qualidade que permita de fato disputarmos e transformarmos a sociedade desigual.

Argumentum, Vitória (ES), v. 8, n.1, p. 27-47, jan./abr. 2016. 


\title{
Breves considerações, nada finais:
}

\author{
"As pulgas sonham em comprar um cão, e os ninguéns com deixar a pobreza, \\ que em algum dia mágico de sorte chova a boa sorte a cântaros; mas a boa sorte \\ não chova ontem, nem hoje, nem amanhã, nem nunca, nem uma chuvinha cai \\ do céu da boa sorte, por mais que os ninguéns a chamem e mesmo que a mão \\ esquerda coce, ou se levantem com o pé direito, ou comecem o ano mudando \\ de vassoura. \\ Os ninguéns: os filhos de ninguém, os donos de nada. \\ Os ninguéns: os nenhuns, correndo soltos, morrendo a vida, fodidos e mal pa- \\ gos: \\ Que não são embora sejam. \\ Que não falam idiomas, falam dialetos. \\ Que não praticam religiões, praticam superstições. \\ Que não fazem arte, fazem artesanato. \\ Que não são seres humanos, são recursos humanos. \\ Que não têm cultura, têm folclore. \\ Que não têm cara, têm braços. \\ Que não têm nome, têm número. \\ Que não aparecem na história universal, aparecem nas páginas policiais da im- \\ prensa local. \\ Os ninguéns, que custam menos do que a bala que os mata." \\ Eduardo Galeano
}

Este artigo tratou de pontes, muros e oceanos. Criou conexões entre as narrativas políticas expressas nas letras das poesias/músicas e nos textos e contextos trabalhados.

A ponte social produzida deve ser considerada sempre no plural. Relações Sul-Sul e NorteSul da/desde América Latina. As relações continentais entre Europa, América, África e Ásia, foram criadas por (e criadoras de) pontes sociais, econômicas e culturais construídas antes de 1500. Mas foi com o descobrimento que um modo de produção específico consolidou na América Latina a acumulação originária que daria força condutora ao capitalismo em geral, e ao capitalismo dependente em particular.

Nas pontes, nos muros e ao longo dos oceanos que circundam América Latina as histórias das resistências e da dominação ganham vida. E ganham o sentido político de quem as conta. Nas pontes, muros e oceanos da América Latina são narrados e/ou silenciados múltiplos acontecimentos históricos. As cidades modernas são apenas a faceta contemporânea das pontes/passagens tecnológicas de um futuro que não consegue invisibilizar o passado no presente.

As fronteiras se movimentam com base na consolidação de outros projetos de integração para além dos mercados e em meio à ação hegemônica destes. $\mathrm{O}$ nacional se esbarra com o continental e internacional, o mercantil se cruza com o uso coletivo, o individual se defronta com o comunal.

Ontem e hoje, essa é a história real da América Latina. Uma história de lutas, resistências, revolutas e revoluções em meio à violência mercantil hegemônica. São povos originários e 
camponeses que guardam em suas caminhadas memórias e histórias daquilo que lhes tocou lutar para preservar e ainda superar.

A colonialidade do saber e do poder (Lander, 2005; Quijano, 2005) ergue-se sob o manto estrutural e estruturante da materialidade da produção mercantil de vida. Base que orienta a dominação para o poder ter, ser mais, de alguns poucos proprietários privados dos meios de produção, sobre o ter, ser menos, de milhões de sujeitos condenados pelo sistema mercantil à submissão e subsunção formal e real. Colonialidades, estas, imersas na perspectiva hegemônica de classes que a consolida.

Ser mais, ser menos é uma ponte construída objetiva e subjetivamente sobre os corpos, as mentes, os territórios dos sujeitos que vivem condicionados à desigual forma de produção e acumulação de riqueza capitalista. Os muros, as pontes e os oceanos manifestos desde a perspectiva do lucro, origem e condição do capitalismo, evidenciam os limites civilizatórios da continuidade da humanidade, dado a irracional utilização do trabalho e da terra como recursos ilimitados. Isto exige novos processos urgentes e conscientes de poder (ser, ter, produzir). Ou é isto, ou a continuidade da barbárie sobre a humanidade será mantida. Pois nada mais violento, bárbaro que a produção de vida baseada na propriedade privada dos meios de produção, com centralidade para a mercantilização dos corpos (sentidos/trabalho) e da terra.

A UNILA assim como as demais construções sociais desenvolvidas na América Latina ao longo dos últimos 515 anos insere-se no contexto abordado relativo às múltiplas pontes, muros e oceanos. A construção de caminhos está aberta. Mas, se será emancipatória ou não, depende do teor da luta, das resistências e das capacidades coletivas de aprendizagens rumo a outros saberes, poderes, quereres.

A UNILA situa-se nas fronteiras. Cabe aos seres sociais que a constroem, e se reconstroem, criar outros rumos, sentidos, para além da recolonização, mercantilização, apropriação privada de produções coletivas/comunais.

Assim como os vulcões - "olhos" naturalmente criados pelo próprio meio para jorrar de dentro da terra, aquilo que se não for expelido pode danificá-la -, a UNILA tem um mesmo sentido dado à produção socialmente construída. Pode definir rumos emancipatórios, em meio ao não revolucionário, capazes de refundar o sentido do conhecimento acadêmico em sua relação com o popular, ou pode permanecer como presença histórica de um processo de dominação que persiste em calar, subsumir, sufocar vozes e projetos.

Como o mundo não está dado, é movimento, lutamos e trabalhamos para a primeira opção. Toda luta e trabalho imerso em uma sociedade desigual, abre passo à possibilidade de se caminhar amanhã, sobre as pontes que fomos capazes de construir como classe ontem e hoje. A UNILA se torna assim um entre vários processos de construção de uma nova ordem potencial capaz de transformar a tendência ao aniquilamento físico-psíquico dos trabalhadores rumo precipício sob a conduta do capital, e reconstruir outros sentidos para as pontes, muros e oceanos que, até então, têm condenado milhões de pessoas à real condição de miséria.

Argumentum, Vitória (ES), v. 8, n.1, p. 27-47, jan./abr. 2016. 


\section{Referências}

CARDOSO, Ciro Flamarion. América pré-colombiana. Rio de Janeiro: Brasiliense, 1982.

CEPAL. Los pueblos indígenas en América Latina: avances en el último decenio y retos pendientes para La garantia de sus derechos. Santiago: Publicación de las naciones unidas, 2014 .

DUSSEL, Enrique. Europa, modernidad e eurocentrismo. Buenos Aires: Clacso, 2000. Disponível em: <http://biblioteca.clacso.edu.ar/clacso/sursur/20100708040738/4_dussel.pdf>. Acesso em: 5 ago. 2015.

ENGELS, Frederich. Sobre o papel do trabalho na transformação do macaco em homem. 1876. Disponível em:

<https://www.marxists.org/portugues/marx/1876/mes/macaco.htm>. Acesso em: 14 ago. 2015 .

FREIRE, Paulo. Pedagogia do Oprimido. 17. ed. Rio de Janeiro: Paz e Terra, 1987.

GALEANO, Eduardo. As veias abertas da América Latina. 44. ed. Rio de Janeiro: Paz e Terra, 1989.

GALEANO, Eduardo. Os demônios do Demônio. Le Monde Diplomatique Brasil, São Paulo, 1o ago. 2005. Disponível em: <http://diplomatique.org.br/acervo.php?id=1279>. Acesso em: 13 de agosto de 2015 .

LANDER, Edgardo. Ciências sociais: saberes coloniais e eurocêntricos. In: LANDER, Edgardo (Org.). A colonialidade do saber: eurocentrismo e ciências sociais: perspectivas latinoamericanas. Buenos Aires: CLACSO, set. 2005. Disponível em:

$<$ http://bibliotecavirtual.clacso.org.ar/ar/libros/lander/pt/Lander.rtf>. Acesso em: 18 ago. 2015 .

MARINI, Ruy Mauro. Dialética da dependência. In: TRASPADINI, Roberta; STÉDILE, João Pedro. Ruy Mauro Marini vida e obra. São Paulo: Expressão Popular, 2011.

MARINI, Ruy Mauro. Subdesarrollo y revolución. Ciudad del México: Era, 1969.

MARX, Karl. O capital. Crítica da economia política. Livro I, O processo de produção de capital, Vol. II. Rio de Janeiro: Bertand Brasil, 1989.

QUIJANO, Anibal. Colonialidade do poder, eurocentrismo e América Latina. In: LANDER, Edgardo (Org.). A colonialidade do saber: eurocentrismo e ciências sociais. Perspectivas latino-americanas. CLACSO, 2005. Disponível em:

<http://bibliotecavirtual.clacso.org.ar/ar/libros/lander/pt/Quijano.rtf>. Acesso em: 5 ago. 2015 . 
RIBEIRO, M. Adelia. Por uma razão decolonial: desafios ético-político-epistemológicos à cosmovisão moderna. Civitas, Porto Alegre, v. 14, n. 1, 2014.

UNILA. Estatuto. [2011]. Disponível em:

<http://www.unila.edu.br/sites/default/files/files/ESTATUTO\%2oUNILA(2).pdf>. Acesso em: 13 ago. 2015.

VITERI, Carlos. “Súmak Káusai. Una respuesta viable al desarrollo”. 2003. Disertación (Licenciatura) Universidad Politécnica Salesiana. Quito, 2003.

WALLERSTEIN, Emanuel. Análisis del sistema mundo. Una introducción. Ciudad del México: Siglo XXI Editores, 2005. 